\title{
EFEITOS DA LEGISLAÇÃO PARA A EDUCAÇÃO DE DOTADOS E TALENTOSOS: O QUE DIZEM OS GESTORES ESCOLARES
}

\author{
LA LEGISLACIÓN A LOS FINES DE LA EDUCACIÓN Y CON TALENTOSOS: \\ LO QUE DICEN LOS DIRECTORES DE ESCUELA
}

\section{EFFECTS OF LEGISLATION FOR GIFTED AND TALENTED EDUCATION: WHAT SCHOOL MANAGERS SAY}

\author{
Rosimeire dos SANTOS ${ }^{1}$ \\ Zenita Cunha GUENTHER ${ }^{2}$ \\ Leandro Osni ZANIOLO ${ }^{3}$
}

RESUMO: O presente artigo é resultado da pesquisa de mestrado que buscou investigar os efeitos da legislação brasileira para a educação dos estudantes com Dotação e Talento retratou e interpretou aspectos da política educacional, no Brasil, para esse público alvo da Educação Especial. Teve como participantes gestores escolares da região do vale do Paranapanema que cursaram o Programa de Formação de Gestores e Educadores, Educação Inclusiva: Direito à Diversidade, promovido pelo MEC. Os resultados indicam que as orientações legais não têm auxiliado na identificação e na oferta de intervenção específica para esses estudantes, evidência a dificuldade na compreensão da terminologia adotada, revela que as ações de identificação se restringem a uma visão fragmentada do processo, aponta a necessidade de formação docente mais consistente para captar sinais de capacidade elevada reconhecendo os diferentes domínios de capacidade humana, bem como a importância de ampliar as recomendações oficiais nessa área, desvinculando, assim, de apenas uma corrente teórica.

PALAVRAS-CHAVE: Política educacional. Dotação e talento. Educação especial.

RESUMEN: Este artículo es el resultado de la investigación de la maestra que investigó los efectos de la legislación brasileña para la educación de los estudiantes con la asignación y Talento representado e interpretado aspectos de la política educativa en Brasil para este público objetivo de la educación especial. Tenido como directores de los centros participantes en la región de Paranapanema valle que asistió a los gestores y educadores programa de entrenamiento, Educación inclusiva: el derecho a la diversidad, patrocinado por el MEC. Los resultados indican que las directrices legales no han ayudado a la identificación y la oferta de intervención específica para estos estudiantes, puesto de manifiesto la dificultad en la comprensión

1 Doutora em Educação (Unesp/Araraquara), membro do Grupo de Pesquisa intitulado Coletivo de Pesquisadores em Políticas Educacionais - COPPE e da Rede de Internacional de Investigação, Intervenção e Avaliação nas Altas Capacidades - REINEVA. m_meiresan@ @otmail

2 PhD em Dotação e Talento. Professora Aposentada da Universidade Federal de Lavras. Supervisora Técnica do CEDET/ASPAT Lavras/MG. Idealizadora da Metodologia CEDET. -

3 Docente no Programa de Pós-Graduação em Educação Escolar - FCL-UNESP/Araraquara. zaniolo@fclar.unesp.br 
de la terminología adoptada, revela que la identificación de las acciones están restringidas a una visión fragmentada del proceso, se señala la necesidad de la formación del profesorado más consistente para capturar la señal de alto rendimiento reconocer los diferentes campos de la capacidad humana, así como la importancia de aumentar las recomendaciones oficiales en esta área, separando por tanto, sólo una corriente teórica.

PALAVRAS-CLAVE: Política educativa. Asignación y talento. La educación especial.

ABSTRACT: This article results from a master's research aiming to investigate effects of the Brazilian laws regulating Special Education in the public school system, focusing on the provisions for Gifted and Talented students. The subjects were school principals and managers from the Paranapanema valley region, who had participated in the Educators Training Program - Inclusive Education: a Right to Diversity, promoted by the Brazilian Ministry of Education - MEC. Results suggest that: a) present official instructions have not helped to identify and/or provide specific intervention for these students; $b)$ there is noticeable difficulty within the school principals/managers in understanding both the given concepts and adopted terminology; the identification practices are entirely restricted to a fragmented view of the process. Conclusions point out the need for more consistent and effective teacher training to help them to capture signs of high ability in the classroom, to recognize different natural ability domains, and the value of scaling up official recommendations and measures to develop practices, disengaged from one single theoretical stream, as it is now.

KEYWORDS: Educational policy. Giftedness. talent. Gifted education.

\title{
Introdução
}

\section{Políticas Educacionais para os mais capazes}

\begin{abstract}
Nas várias assembleias, convenções e reuniões internacionais, o Brasil tem regularmente assumido o compromisso de respeitar os direitos das crianças e promover o desenvolvimento e educação para toda a população. Em 1990, na Conferência de Jomtien, todos os países, inclusive o Brasil, se comprometeram a envidar esforços para desenvolver plenamente as potencialidades de cada criança, jovem ou adulto. Portanto, intenção existe, mas intenção e boa vontade não bastam. Nosso país tem sido lembrado sobre a presteza com que os governantes assumem compromissos e aceitam princípios em âmbito internacional, sem nada fazer de concreto para levar à população o que é resolvido. Até que ponto isso acontece em Educação Especial para dotados e talentosos? (GUENTHER, 2006, p. 28).
\end{abstract}


O Atendimento Educacional Especializado para crianças e jovens com capacidade elevada é referendado pela legislação brasileira vigente na Constituição da República Federativa do Brasil, de 1988; na Lei de Diretrizes e Bases da Educação Nacional - LDBEN n 9.394/96 e sua alteração pela Lei n 12.796/2013; existem várias normas delineadas em Pareceres, Instruções e Diretrizes, que reconhecem a importância e a necessidade de oferecer oportunidades e desenvolver práticas destinadas ao atendimento especializado como resposta a essa demanda. No entanto, é também verdade que como disse Helena Antipoff (1973) “[...] de pouca valia serão os decretos, programas e dispositivos oficiais [...] que permanecerão como letras mortas sem atingir o cerne da instrução, sem modificar o que existe". (ANTIPOFF, 1973).

No Brasil, a primeira iniciativa para oferecer atendimento às pessoas mais capazes foi em 1945, na Sociedade Pestalozzi, encabeçada por Helena Antipoff, que influenciou consideravelmente toda a Educação Especial nessa área. Seus estudos e considerações resultaram no primeiro registro federal ocorrido na Lei 4.024/61 (BRASIL/1961), que dedicou no Título X - Da Educação de Excepcionais - artigo 88 e 89.

Delou (2007) diz que o reflexo da utilização da palavra excepcional, cunhada por Antipoff, referindo-se tanto aos deficientes intelectuais, quanto aos mais capazes e aos que tinham problemas de conduta, na época, fez com que a Lei atentasse apenas ao tratamento essencialmente clínico a ser dado aos excepcionais. Portanto, pode-se entender que essa primeira Lei não chegou a tocar efetivamente na educação para os dotados e talentosos 4 .

Guenther (2006, 2011), referindo-se a Helena Antipoff, diz que a autora também teve cuidado na escolha das palavras, sobretudo na Educação Especial. O termo excepcional era utilizado para diferenciar crianças e jovens que não correspondem à norma do grupo.

No Brasil, as primeiras menções à educação dos mais capazes empregaram o termo supranormal em oposição ao oposto linguístico infranormal. Porém, o aumento das publicações americanas sobre a educação para os mais capazes, nas décadas de 50 e 60 do século XX, espalharam-se pelo mundo todo, inclusive no Brasil, quando entra no cenário brasileiro o termo superdotado, tradução inapropriada de Giftedness (Dotação).

${ }_{4}^{4}$ Terminologia utilizada para definir esse público alvo da Educação Especial adotada pela Metodologia Caminhos para Desenvolver Potencial e Talento Guenther (2011). 
Na década seguinte, a Lei 5.692/715 (BRASIL, 1971) adota legalmente, pela primeira vez no país, a palavra Superdotação, recomendando que os superdotados deviam receber tratamento especial, de acordo com as normas fixadas pelos competentes Conselhos de Educação ${ }^{6}$. Essa Lei altera a LDB 4.024/61 no tangente à reforma do ensino $\left(1^{\circ}\right.$ e $\left.2^{\circ} \mathrm{Grau}\right)$ e ao definir tratamento especial.

Em 1973, o MEC cria o Centro Nacional de Educação Especial - CENESP, responsável pela gerência da Educação Especial no Brasil. Desse modo, durante 25 anos, a matéria em pauta foi tratada em sucessivos Pareceres do Conselho Federal de Educação (CFE/MEC), atualmente Conselho Nacional de Educação, versando sobre diferentes ações. De acordo com o que mostra o quadro 01 a seguir:

Quadro 1: Pareceres do Conselho Federal de Educação (CFE/MEC)

\begin{tabular}{|c|c|}
\hline PARECER & RECOMENDAÇÃO \\
\hline $\mathrm{N}^{\mathrm{o}} 255$, de $09 / 03 / 1972$ & $\begin{array}{l}\text { Destaca que o progresso do estudante deve atender a ritmo próprio de } \\
\text { aprendizagem e a diversos interesses e aptidões. }\end{array}$ \\
\hline $\mathrm{N}^{\circ} 436$, de $09 / 05 / 1972$ & $\begin{array}{l}\text { Admite matricula condicional de aluno superdotado em curso superior, com } \\
\text { prazo de até dois anos para apresentação de prova de conclusão do ensino de } \\
\text { segundo grau, desde que reconhecida sua superdotação antes da inscrição no } \\
\text { vestibular. }\end{array}$ \\
\hline $\mathrm{N}^{\mathrm{o}} 681$, de $07 / 05 / 1973$ & $\begin{array}{l}\text { Oportunamente fixar o conceito e as formas de apurar o superdotado, a partir do } \\
\text { que baixariam os Conselhos de Educação, as normas sobre a matéria para os seus } \\
\text { sistemas estaduais de ensino. }\end{array}$ \\
\hline $\mathrm{N}^{\mathrm{o}} 711$, de $02 / 09 / 1987$ & $\begin{array}{l}\text { Estabelece ações de atendimento ao superdotado: } \\
\text { 1. Conceitos e formas de apurar a superdotação; } \\
\text { 2. Descentralização de competência para declarar a superdotação; } \\
\text { 3. Procedimentos para identificação; } \\
\text { 4. Modalidades de atendimento; } \\
\text { 5. Formação de Recursos Humanos; } \\
\text { 6. Estudos e Pesquisas; } \\
\text { 7. Constituição da Coordenadoria Nacional; } \\
\text { 8. Envolvimento das Secretarias e dos Conselhos de Educação, e. } \\
\text { 9. Participação da Família, Escola, Empresa e Comunidade, e enuncia } \\
\text { os princípios da Educação Especial: participação, integração, normalização, } \\
\text { interiorização e simplificação. }\end{array}$ \\
\hline
\end{tabular}

Fonte: Elaborado pelos autores.

${ }^{5}$ Lei 5.692, de 11 de agosto de 1971, altera a LDBEN nº 4024/61 - reorganizou todo o ensino primário e secundário.

${ }^{6}$ Brasil, 1971, Artigo $9^{\circ}$. Os alunos que apresentem deficiências físicas ou mentais, os que se encontrem em atraso considerável quanto à idade regular de matrícula e os superdotados deverão receber tratamento especial, de acordo com as normas fixadas pelos competentes Conselhos de Educação. (Grifo nosso) 
Sob a égide integracionista, as ações que foram impulsionadas, tanto para o atendimento às deficiências como para as crianças e aos jovens mais capazes, estavam ligadas às configurações assistencialistas e a algumas poucas iniciativas isoladas do Estado. Os estudantes mais capazes que têm acesso ao ensino regular, não encontram ações do poder público para o atendimento especializado, e nessas condições os mais capazes não encontram as opções educativas necessárias às suas características.

Saviani (1987), discorrendo sobre a análise dos textos legais, quando são apresentados sistêmica e funcionalmente, diz que: "acabam por enfatizar o ideal em detrimento do real, tomando o deve-ser pelo ser, a norma pelo fato [...] não basta ater-se à letra da lei; é preciso captar seu espírito. Não é suficiente analisar o texto; é preciso examinar o contexto. Não basta ler as linhas, é necessário ler as entrelinhas". (SAVIANI, 1987, p.134).

Dessa forma, faz-se relevante revisitá-las, a fim de entender os meandros da construção histórica e os modelos de atendimento por eles vinculados, perceber o que mudou ou o que permaneceu. E talvez assim compreender porque de permanecem como letras mortas.

Após a aprovação da LDBEN 9.394/96 seguiram-se outros documentos oficiais, destinados a orientar e normatizar o que aparentemente permanecera insuficiente ou impreciso.

A Resolução CNE/CEB no 2/20017, embora dando ênfase maior na área de deficiência do que de dotação, explicita no artigo $2^{\circ}$ a obrigatoriedade de atenção especializada aos alunos e delega aos Sistemas de Ensino o estabelecimento de sua própria política e diretrizes.

O Plano Nacional de Educação (PNE $n^{\circ}$ 10.172/2001) estabeleceu objetivo e metas para os sistemas de ensino, prevendo o atendimento especializado ao público alvo da educação especial, nas áreas de déficit, na formação de professores e na acessibilidade física.

No período de elaboração do Plano Nacional de Educação (PNE $n^{\circ}$ 10.172/2001), entre 1996 e 1998, os dados estatísticos referentes à educação dos mais capazes, Censo Escolar de 1998 (MEC/INEP), que sustentaram as discussões para a elaboração do Plano, revelam que apenas 0,003\% das crianças e jovens com alta capacidade eram identificados no país (Sinopse Estatística da Educação Básica / Censo

7 CNE/CEB. Resolução no 2/2001, de 11 de setembro de 2001. Institui Diretrizes Nacionais para a Educação Especial na Educação Básica. Brasília, Conselho Nacional de Educação, 2001. 
Escolar 1998, do MEC/INEP). O PNE n 10.172 / 2001 apontava que "o grande avanço que a década da educação deveria produzir seria a construção de uma escola inclusiva que garanta o atendimento à diversidade humana".

Uma das metas estabelecida pelo PNE 10.172 / 2001 era a implantação gradativa, a partir do primeiro ano do plano, de programas de atendimento aos alunos com alta capacidade nas áreas artística, intelectual ou psicomotora, o que não se consolidou.

Para os estudantes com dotação e talento, os quais já estão nas classes comuns, não há qualquer referência ao atendimento especializado.

Em 2003, é implantado pelo MEC o Programa Educação Inclusiva: Direito à Diversidade, a fim de promover a formação de gestores e professores nos municípios brasileiros, visando à garantia do acesso de todos à escolarização, ao atendimento especializado e à acessibilidade. Esse programa sugere, como base organizacional, a esperançosa estratégia de multiplicação ${ }^{8}$, dinamizada por polos de referência nas diferentes regiões do Brasil, com a intenção de disseminar a política de construção de sistemas educacionais inclusivos e apoiar o processo de implantação e consolidação.

Outra iniciativa de oferecer formação aos docentes, com o foco na área de alta capacidade ocorreu em 2005, promovida pela Secretaria de Educação Especial do Ministério da Educação, Ministério da Educação e Cultura, foi a criação dos Núcleos de Atividades de Altas Habilidades / Superdotação - NAAHS, destinados a oferecer atendimento aos professores, aos pais e aos educandos com altas habilidades e superdotação. Desenvolvido em parceria do MEC financiado por um convênio específico da UNESCO com as Secretarias de Educação de cada Estado da Federação, configurou um referencial oficial para o atendimento educacional especializado, investindo na implantação de políticas públicas inclusivas no atendimento educacional dos alunos superdotados. (sic) (BRASIL, 2010, p.15).

Também chama a atenção o fato da Professora Fleith (2008) considerar muito importante a criação dos Núcleos de Atividades de Altas Habilidades / Superdotação (NAAHS), e relevante a publicação, por ela mesma editada em 2007, da coletânea de quatro volumes, intitulada A Construção de Práticas Educacionais para Alunos com

8 A estratégia de multiplicação está presente no documento orientador, que assinala, embora sem verificação empírica, que o efeito multiplicador é efetivo ao garantir a reprodução de conteúdo e é mais econômico, na medida em que forma uma pessoa que deverá multiplicar a informação para muitos. (BRASIL, 2008) 
Altas Habilidades / Superdotação, publicada pela Secretaria de Educação Especial, disponível no portal do Ministério da Educação.

A Resolução CNE/CEB no $04 / 2009^{9}$ e a Nota Técnica SEESP/GAB/N ${ }^{\circ}$ $11 / 2010^{10}$ indicam as diretrizes operacionais para o Atendimento Educacional Especializado na Educação Básica, definindo como Público Alvo, no artigo $4^{\mathrm{a}}$, inciso III, “[...] alunos com altas habilidades/superdotação: aqueles que apresentam um potencial elevado e grande envolvimento com as áreas do conhecimento humano, isoladas ou combinadas: intelectual, liderança, psicomotora, artes e criatividade". Na ocasião essa definição foi criticada por Guenther (2011) como uma adaptação mutilada das ideias de Joe Renzulli, enfatizando que não caberia a um órgão central adotar posições teóricas, mas simplesmente estabelecer a política pública, focalizada na obrigação de implantar o serviço indicação da fonte de recursos disponibilizados.

Por essa legislação o AEE (Atendimento Educacional Especializado) seria realizado, prioritariamente, na sala de recursos multifuncionais da própria escola, ou em outra escola de ensino regular, no turno inverso ao que o aluno frequentasse, não sendo consideradas substitutivas as classes comuns. Reconhece, oficialmente, que o atendimento pode ser realizado também em Centro de Atendimento Educacional Especializado da rede pública ou de instituições comunitárias, confessionais ou filantrópicas sem fins lucrativos, conveniadas à Secretaria de Educação ou órgão equivalente dos Estados, Distrito Federal ou dos Municípios. (BRASIL, 2009 art.5º [grifo nosso].

$\mathrm{O}$ artigo $7^{\circ}$ da Resolução CNE/CEB n ${ }^{\circ}$ 04/2009 indica que os educandos com altas habilidades/superdotação receberão enriquecimento curricular nas escolas públicas em interface com os NAAHS (Núcleos de Atividades em Altas Habilidades/ Superdotação), bem como nas instituições de ensino superior que promovam pesquisa, arte e esportes. (BRASIL, 2009). Guenther (2011) critica novamente a doção de metodologia específica - enriquecimento - em detrimento de outras, nem sequer mencionadas como possibilidade. Também a identificação dos alunos, na legislação brasileira, vem sida regularmente alterada, ao longo do tempo, e da mesma forma, as mudanças permaneceram mais no discurso do que na efetivação das ações previstas.

${ }^{9}$ CNE/CEB. Resolução no 4/2009, de 02 de outubro de 2009. Institui Diretrizes Operacionais para o Atendimento Educacional Especializado na Educação Básica, modalidade Educação Especial.

10 Nota Técnica - 11/2010 Dá Orientações para a institucionalização da Oferta do Atendimento Educacional Especializado - AEE em Salas de Recursos Multifuncionais, implantadas nas escolas regulares. 
Assim a concepção de Educação Especial sofreu mudanças significativas ao longo do tempo, principalmente após definido o ideário da Educação Inclusiva. Desde Educação dos Excepcionais (1961), Tratamento Especial (1971), Educação Especial (1978) como modalidade de educação escolar, chega-se ao atual momento Educação Especial, na perspectiva da Educação Inclusiva. Porém, apesar de tentativas relativamente vazias de remediar tal conotação, o sentido geral permaneceu o mesmo: aproximar o aluno "diferente" ao grupo normal. Essa ideia que favorece ao excepcional deficiente tem, para o excepcional mais dotado efeito negativo em longo prazo, pois aproximá-lo do grupo normal dificulta ou impede seu desenvolvimento.

Para completar, a LDBEN 9394/96, na sua versão mais recente, a Lei 12.796/2013, que reforça a previsão para a Educação Especial, curiosamente oficializa a denominação altas habilidades ou superdotação, criticada por Guenther e Rondini (2012), já presente em outros documentos, mas não da lei original, conhecida como "Lei Darci Ribeiro”, LDBEN 9394/96. (BRASIL, 1996)

O presente estudo, com a finalidade de observar e aferir o visível descompasso entre o que é estabelecido nos pressupostos legais e o que efetivamente acontece nas escolas em relação à educação para dotados e talentosos tomou como ponto de partida um levantamento das normativas legais para esse atendimento, iniciando pela primeira Lei de Diretrizes e Bases da Educação Nacional nº 4.024/61 como exposto no quadro 02 a seguir:

Quadro 2: Síntese das normativas oficiais referentes aos estudantes com Alta Capacidade no Brasil

\begin{tabular}{|c|c|c|c|c|}
\hline Ano & Documento & $\begin{array}{l}\text { Atendimento } \\
\text { Educacional }\end{array}$ & Terminologia & Local de Atendimento \\
\hline 1961 & $\begin{array}{l}\text { Lei de Diretrizes e } \\
\text { Bases da Educação } \\
\text { Nacional } n^{\circ} 4.024 / 61 .\end{array}$ & $\begin{array}{l}\text { Educação dos } \\
\text { Excepcionais. }\end{array}$ & Excepcionais. & $\begin{array}{l}\text { A Educação dos } \\
\text { Excepcionais deve, no que } \\
\text { for possível, enquadrar-se no } \\
\text { sistema geral de educação. }\end{array}$ \\
\hline 1971 & $\begin{array}{l}\text { Lei que altera a } \\
\text { LDBEN } 4.024 / 61, \\
\text { referente à } \\
\text { organização para os } \\
\text { ensinos de } 1^{\circ} \text { e } 2^{\circ} \\
\text { graus. }\end{array}$ & Tratamento Especial. & $\begin{array}{l}\text { Alunos com } \\
\text { deficiência física, } \\
\text { mental ou os que se } \\
\text { encontrem em atraso } \\
\text { considerável quanto à } \\
\text { idade regular de } \\
\text { matrícula e os } \\
\text { superdotados. }\end{array}$ & $\begin{array}{l}\text { De acordo com normas } \\
\text { fixadas pelos competentes } \\
\text { Conselhos de Educação. }\end{array}$ \\
\hline 1988 & Constituição Federal & $\begin{array}{l}\text { Atendimento } \\
\text { Educacional } \\
\text { Especializado. }\end{array}$ & $\begin{array}{l}\text { Portadores de } \\
\text { Deficiência. }\end{array}$ & $\begin{array}{l}\text { Preferencialmente, na rede } \\
\text { de ensino. }\end{array}$ \\
\hline 1989 & Lei $n^{\circ} 7.853 / 89$ (Lei & Integração no sistema & Pessoas portadoras de & Inserção no sistema \\
\hline
\end{tabular}




\begin{tabular}{|c|c|c|c|c|}
\hline & de Integração). & $\begin{array}{l}\text { educacional dos } \\
\text { estudantes da } \\
\text { educação especial. }\end{array}$ & deficiência. & $\begin{array}{l}\text { educacional das escolas } \\
\text { privadas e públicas; } \\
\text { matrícula compulsória em } \\
\text { cursos regulares para } \\
\text { pessoas capazes de se } \\
\text { integrar. }\end{array}$ \\
\hline 1994 & $\begin{array}{l}\text { Política Nacional de } \\
\text { Educação Especial. }\end{array}$ & $\begin{array}{l}\text { Educação } \text { Especial: } \\
\text { processo que visa } \\
\text { promover } \\
\text { desenvolvimento das } \\
\text { potencialidades das } \\
\text { pessoas portadoras de } \\
\text { deficiência, condutas } \\
\text { típicas ou de altas } \\
\text { habilidades. }\end{array}$ & $\begin{array}{lr}\text { Portadores } & \text { de } \\
\text { Deficiência } & \text { (mental, } \\
\text { visual, } & \text { auditiva, } \\
\text { física, múltiplas), } \\
\text { portadores } \\
\text { condutas típicas e } \\
\text { portadores de altas } \\
\text { habilidades. }\end{array}$ & $\begin{array}{l}\text { Apoiar o sistema regular de } \\
\text { ensino para integração e } \\
\text { estimular a parceria com } \\
\text { ONGs especializadas. }\end{array}$ \\
\hline 1996 & $\begin{array}{l}\text { Lei de Diretrizes e } \\
\text { Bases da Educação } \\
\text { Nacional nº 9.394/96. }\end{array}$ & $\begin{array}{l}\text { Atendimento } \\
\text { Educacional } \\
\text { Especializado. }\end{array}$ & $\begin{array}{l}\text { Aluno portador de } \\
\text { Necessidades } \\
\text { Especiais. }\end{array}$ & $\begin{array}{l}\text { Preferencialmente, na rede } \\
\text { regular de ensino, em } \\
\text { classes, escolas ou serviços } \\
\text { especializados, sempre que, } \\
\text { em função das condições } \\
\text { específicas dos alunos, não } \\
\text { for possível sua integração } \\
\text { nas classes comuns. }\end{array}$ \\
\hline 2001 & $\begin{array}{lr}\text { Diretrizes } & \text { Nacionais } \\
\text { para a } & \text { Educação } \\
\text { Especial } & - \text { Resolução } \\
\text { no } 02 .\end{array}$ & $\begin{array}{lr}\text { Educação } & \text { Especial } \\
\text { modalidade } & \text { da } \\
\text { Educação Escolar. }\end{array}$ & $\begin{array}{lr}\text { Educandos } & \text { com } \\
\text { Necessidades } & \\
\text { Educativas Especiais. } \\
{[\ldots] \text { III }-} & \text { altas } \\
\text { habilidades } & / \\
\text { superdotação, grande } \\
\text { facilidade r de } \\
\text { aprendizagem que } \\
\text { leve a dominar } \\
\text { rapidamente } \\
\text { conceitos, } \\
\text { procedimentos } \\
\text { atitudes. }\end{array}$ & $\begin{array}{l}\text { Atendimento deve ser } \\
\text { realizado em classe comum, } \\
\text { em qualquer etapa ou } \\
\text { modalidade da educação } \\
\text { básica. }\end{array}$ \\
\hline 2001 & $\begin{array}{l}\text { Plano Nacional } \mathrm{da} \\
\text { Educação - Lei } \mathrm{n}^{\circ} \\
\text { 10.172/2001. }\end{array}$ & Educação Especial & $\begin{array}{l}\text { Pessoa com } \\
\text { necessidades } \\
\text { especiais no campo } \\
\text { da aprendizagem, } \\
\text { originadas quer de } \\
\text { deficiência física, } \\
\text { sensorial, mental ou } \\
\text { múltipla, quer de } \\
\text { características como } \\
\text { altas habilidades, } \\
\text { superdotação ou } \\
\text { talento. }\end{array}$ & $\begin{array}{l}\text { Integração/inclusão no } \\
\text { sistema regular e, se isso não } \\
\text { for possível em função das } \\
\text { necessidades do educando, } \\
\text { realizar o atendimento em } \\
\text { classes e escolas } \\
\text { especializadas. }\end{array}$ \\
\hline
\end{tabular}

Fonte: autores 
Quadro 02: continuação - Síntese das normativas oficiais referentes aos estudantes com Alta Capacidade no Brasil

\begin{tabular}{|c|c|c|c|c|}
\hline Ano & Documento & $\begin{array}{l}\text { Atendimento } \\
\text { Educacional }\end{array}$ & Terminologia & Local de Atendimento \\
\hline 2009 & $\begin{array}{l}\text { Diretrizes } \\
\text { Operacionais } \\
\text { para o } \\
\text { Atendimento } \\
\text { Educacional } \\
\text { Especializad } \\
\text { o. Resolução } \\
\mathrm{n}^{\circ} 04 / 2009 \text {. }\end{array}$ & Educação Especial & $\begin{array}{l}\text { Pessoa com Deficiência, } \\
\text { Transtorno Global do } \\
\text { Desenvolvimento e Altas } \\
\text { Habilidades } \\
\text { Superdotação (aquelas } \\
\text { que apresentam um } \\
\text { potencial elevado e } \\
\text { grande envolvimento } \\
\text { com as áreas do } \\
\text { conhecimento humano, } \\
\text { isoladas ou combinadas: } \\
\text { intelectual, liderança, } \\
\text { psicomotora, artes e } \\
\text { criatividade). }\end{array}$ & \begin{tabular}{l}
\multicolumn{1}{c}{ AEE- } \\
Atendimento Educacional \\
Especializado em Salas de \\
Recursos Multifuncionais, \\
Centros Especializados e \\
Instituições \\
Especializadas.
\end{tabular} \\
\hline 2013 & $\begin{array}{l}\text { Lei }^{\circ} \\
12.796, \text { que } \\
\text { altera a } \\
\text { LDBEN no } \\
\text { 9394/96. }\end{array}$ & $\begin{array}{l}\text { Modalidade da } \\
\text { Educação Escolar }\end{array}$ & $\begin{array}{l}\text { Educandos com } \\
\text { deficiência, transtorno } \\
\text { global do } \\
\text { desenvolvimento e altas } \\
\text { habilidades ou } \\
\text { superdotação. }\end{array}$ & $\begin{array}{l}\text { Como alternativa } \\
\text { preferencial, a ampliação } \\
\text { do atendimento ao público } \\
\text { alvo na própria rede } \\
\text { pública regular de ensino, } \\
\text { independentemente do } \\
\text { apoio às instituições } \\
\text { especializadas. }\end{array}$ \\
\hline 2015 & $\begin{array}{l}{\text { Lei } \mathrm{n}^{\circ}} \\
13.234, \text { que } \\
\text { altera a } \\
\text { LDBEN no } \\
\text { 9394/96. }\end{array}$ & $\begin{array}{l}\text { Modalidade da } \\
\text { Educação Escolar }\end{array}$ & $\begin{array}{l}\text { Educandos com } \\
\text { deficiência, transtorno } \\
\text { global do } \\
\text { desenvolvimento e altas } \\
\text { habilidades ou } \\
\text { superdotação. }\end{array}$ & \begin{tabular}{l}
\multicolumn{1}{c}{ Institui cadastro } \\
nacional de alunos com \\
altas habilidades ou \\
superdotação matriculados \\
na educação básica e na \\
educação superior, a fim \\
de fomentar a execução de \\
políticas públicas \\
destinadas ao \\
desenvolvimento pleno das \\
potencialidades desse \\
alunado.
\end{tabular} \\
\hline
\end{tabular}

Fonte: Elaborado pelos autores.

O reconhecimento de educandos mais capazes, e o direito à educação, ficam evidentes nos documentos legais. No entanto, esse levantamento revela que o preceito legal não tem auxiliado a reconhecê-los na escola. A legislação orienta aos sistemas de ensino público que estabeleçam sua própria política para a ação, mas para o estudante mais capaz isso não acontece, em razão do próprio MEC disseminar orientação especifica.

Ainda mais, existe uma alegada priorização em relação à ideia de que a criança com dotação e talento pode esperar indefinidamente, ou caminhar sozinha no seu 
desenvolvimento. Desse modo, as crianças com deficiência têm primazia temporal. Em realidade,

[...] o que se verifica é a quase total ausência dos sistemas públicos no que diz respeito à assistência educacional aos alunos mais capazes e talentosos, a não ser por alguns poucos programas esparsos ou iniciativas no contexto de Secretarias de Educação e Universidades Públicas. Essa ausência é às vezes perpetuada pela consciência de que a área de Educação Especial para dotação e talento não é suficientemente conhecida em nossos meios. Mas essa situação tende a permanecer, se não for estabelecida uma prática consistente e significativa que permita a geração de estudos e produção de conhecimento. (GUENTHER, 2006 a, p.31)

Por conseguinte, analisando o panorama das políticas públicas percebe-se subjacente uma base ideológica. Se de fato as políticas educacionais e as diretrizes organizacionais estão impregnadas de intencionalidade, ideias, valores, atitudes aparentemente destinadas a influenciar as escolas e os sistemas de ensino na configuração de suas práticas e na concepção de sujeito, reconhecendo a importância da educação para as crianças e jovens com dotação e talento, por qual motivo essas ações não estão sendo efetivadas.

Essa temática necessita ser discutida nos meios profissionais e escolares, a fim de assimilar e ampliar o conhecimento científico na área. Pode-se perguntar não apenas o que as ideias aconselham, mas, principalmente, refletir sobre em que bases se sustentam, para que e por que existem, e qual sua efetividade. As respostas a essas questões demandam, automaticamente, a definição de base teórica relacionada à identificação e ao desenvolvimento das potencialidades dos estudantes mais capazes.

Parece lógico que as práticas são as balizas que conferem significado à concepção que se tem sobre a educação dos mais capazes e, portanto, servem de respaldo às ações efetivas de atendimento. Assim sendo, faz-se imprescindível compartilhar conhecimentos respaldados na ciência e estabelecer conceitos mais precisos referentes à identificação e desenvolvimento de crianças e jovens com dotação e talento. Quando efetivamente o conhecimento auxilia, direciona e determina a maneira como os professores reconhecem sinais de capacidade elevada, eles se valem dessa saber nas suas intervenções.

Em nosso país, os estudantes dotados e talentosos continuam representando um número ínfimo nas estatísticas. Ao que parece, às ações implantadas não se efetivaram, muito menos modificaram a posição das escolas e a atitude dos professores, afirmado por Delou (2012) e Guenther (2013). A prevalência esperada nos sistemas educativos 
varia consideravelmente: segundo a Organização Mundial da Saúde, em torno de 1 a 3\%; pela Lei da Probabilidade de 3 a 5\% (Guenther, 2011); e pela teoria chamada dos Três Anéis, de Renzulli (2004) de 15 a 30\%. Os dados do Censo de 2010 (Delou, 2012) mostram existência de 0,01\%, ou seja, 9.208 estudantes atendidos, percentual muito aquém do esperado, em qualquer base teórica.

Guenther (2013) na Audiência Pública da Câmara dos Deputados (Brasília) sobre a Política Pública para Alunos com Altas Habilidades / Superdotação, apresenta o número de alunos em intervenção educativa no CEDETs de Lavras/MG (367 estudantes), Poços de Caldas/MG (204 estudantes), Assis/SP (182 estudantes), São José do Rio Preto/SP (43 estudantes); no PIT - Programa de Incentivo ao Talento ligado à Universidade Federal de Santa Maria/RS (34 estudantes) e o NAAHS de Santa Catarina (30 estudantes). Apresenta o número de escolas envolvidas no processo 94 unidades nos CEDETs, já nos outros dois programas esses dados não aparecem. Os dados evidenciam que os Centros para o Desenvolvimento do Potencial e Talento (CEDETs) apresentam percentual mais alto em relação aos outros programas, totalizando 796 estudantes recebendo intervenção educativa especifica, portanto perto de $9 \%$ de todos os alunos localizados no país estão nos 4 CEDETs em funcionamento.

Outra questão abordada pelas pesquisadoras diz respeito à falta de formação específica. A pouca formação que existe é realizada por as ações que acontecem em congressos e encontros sobre o tema, os quais permanecem na superfície teórica, não estabelecem continuidade das ações de identificação e de intervenção nas escolas.

O programa de formação de gestores e educadores - Educação Inclusiva: direito à diversidade - implantado pelo MEC, mencionado anteriormente, buscou promover um amplo processo de formação de gestores e educadores nos municípios brasileiros. Entretanto, o que se percebe é que tal Programa não parece ter conseguido mudar o quadro de identificação e atendimentos aos mais capazes, e foram desaparecendo, ou se modificando, como se pode ver na subseção a seguir, focalizando um dos Polos participantes. Embora seja apenas um Polo, em um universo de 168 polos participantes, os trabalhos foram organizados a partir do documento orientador do programa, que norteou a formação nos outros polos.

\section{Programa de Formação de Gestores e Educadores}


Em relação às temáticas abordadas, o quadro a seguir apresenta os temas apresentados no período de 2003 a 2006:

Quadro 3 - Temas apresentados nos Seminários Nacionais de Formação da SEESP/MEC

\begin{tabular}{|l|l|}
\hline ANO & \multicolumn{1}{c|}{ TEMÁTICAS DISCUTIDAS NA FORMAÇão } \\
\hline 2003 & $\begin{array}{l}\text { Fundamentação filosófica e técnico-científica. } \\
\text { Difusão de conhecimento sobre a educação inclusiva. } \\
\text { Disseminação da política de educação inclusiva. }\end{array}$ \\
\hline $\mathbf{2 0 0 4}$ & $\begin{array}{l}\text { A diversidade humana na escola. } \\
\text { Valores e paradigmas na atenção às pessoas com deficiência. } \\
\text { Fundamentos legais para a impantação do sistema educacional inclusivo. } \\
\text { Concepçães, princípios e diretrizes de um sistema educacional inclusivo: o município, a } \\
\text { escola e a família. }\end{array}$ \\
\hline $\mathbf{2 0 0 5}$ & Formação docente a partir das áreas específicas da Educação Especial. \\
\hline $\mathbf{2 0 0 6}$ & Coleção Saberes e Práticas da Inclusão da Educação Infantil e do Ensino Fundamental. \\
\hline
\end{tabular}

Fonte: Elaborado pela pesquisadora com base nos documentos de formação da SEESP/MEC, Brasília (BRASIL, 2009).

Após 2007, o programa sofreu modificações e, em 2008, os recursos disponibilizados aos municípios-polos passaram a fazer parte do Plano de Metas Todos pela Educação, vinculando sua implantação à adesão ao Plano de Ações Articuladas (PAR).

Observa-se que, em 2007, os eixos temáticos desenvolvidos foram: Inclusão; Escola e Família: Um Compromisso Comum em Educação; Orientações e Marcos Legais para a Inclusão; Atendimento Educacional Especializado para Alunos com Deficiência, Transtorno Geral de Conduta e Altas Habilidades / Superdotação; Tecnologia Assistiva no Processo Educacional. (BRASIL, 2009, p. 4).

Em 2008, os encontros dessa etapa foram elaborados para atender aos seguintes temas: Política Nacional de Educação Inclusiva; Atendimento Educacional Especializado; Deficiência Intelectual; Deficiência Física; Deficiência Visual; Autismo; Altas Habilidades/Superdotação. (BRASIL, 2009, p. 3).

Com a aprovação do Decreto $n^{\circ} 7.690 / 2011$, que dá nova estrutura regimental ao MEC, a SEESP (Secretaria de Educação Especial) é extinta e passa a integrar a SECADI (Secretaria de Educação Continuada, Alfabetização, Diversidade e Inclusão), essa Secretaria objetiva contribuir para o desenvolvimento de sistemas inclusivos de 
ensino, voltados à valorização das diferenças e da diversidade, à promoção da educação inclusiva, dos direitos humanos e da sustentabilidade sócio ambiental, visando à efetivação de políticas públicas transversais e Intersetoriais. (BRASIL, 2013)

Ao verificar as temáticas e, principalmente, as bases filosóficas do programa atrelado à estratégia de multiplicação, observa-se a continuação de conhecimentos pensados fora do contexto das diversidades sociais, econômicas, políticas e culturais do país.

Corazza (2005), quando assinala que os currículos oficiais baseiam-se no princípio de uma totalizadora identidade (identidade nacional), e embora reconheça os diferentes, quer uma identidade nacional, princípio que, por seu caráter unificador, pode trazer dificuldades à compreensão de identidade e provocar prejuízos às diferenças (CORAZZA, 2005, p.105).

As concepções se constituem no decorrer do processo de formação, tanto pessoal como profissional; na área de dotação e talento, especificamente, verifica-se concepções fundamentadas em crenças arraigadas por mitos, por práticas e ideário já demolidos pelo conhecimento científico. O conhecimento científico que infelizmente não chegam até a escola.

Buscando ampliar a reflexão sobre essa questão, o presente estudo deu "voz" aos gestores educacionais que participaram do IX Curso de Formação de Gestores e Educadores, Educação Inclusiva: Direito à Diversidade, Polo de Ourinhos - SP, ouvindo esses profissionais no tocante às políticas educacionais para a educação dos dotados e talentosos. Participaram da pesquisa todos os gestores presente, destes $80 \%$ havia cursado o programa de formação, nas edições do curso de 2007 a 2014.

Em relação às temáticas abordadas no curso de formação, apresentadas no quadro três e sua ampliação em 2008, com a Política Nacional de Educação Especial na Perspectiva da Educação Inclusiva, os dados do Polo de Ourinhos/SP revelam a ampliação em relação às temáticas abordadas apresentadas no gráfico 01:

Gráfico 1:Temáticas Abordadas no Programa Formação de Gestores e Educadores, Educação Inclusiva: Direito à Diversidade, Polo de Ourinhos - SP. 


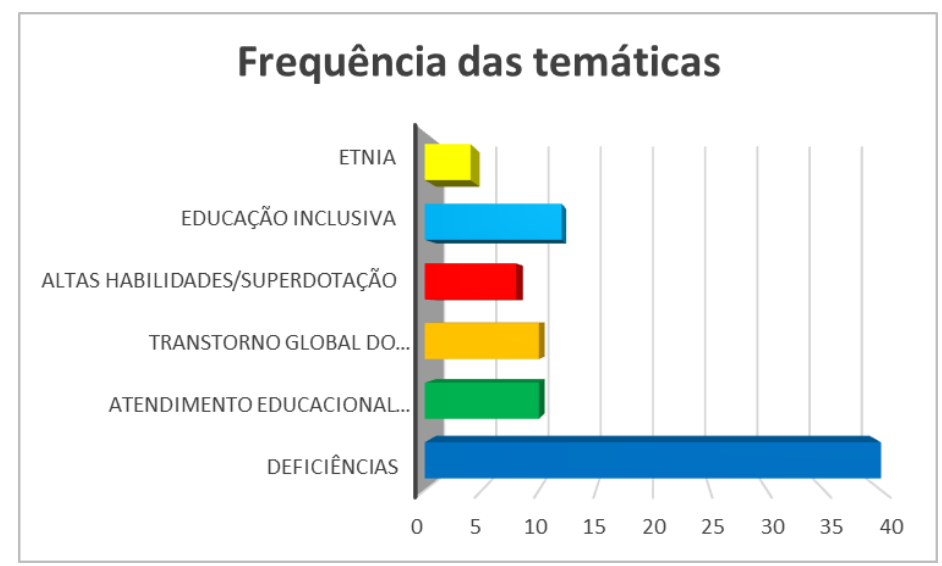

Fonte: Elaborado pelos autores.

O documento oficial de avaliação do programa (BRASIL, 2013) aponta a predominância da temática da Educação Especial nas formações nos polos, ainda que se observe, após 2012, o empenho em utilizar temáticas sugeridas no documento orientador.

No tocante à temática alta capacidade, os documentos de divulgação dos encontros descrevem que as discussões giraram em torno dos princípios contidos nos documentos legais e promoveram discussões voltadas à terminologia e aos processos de identificação e intervenção educativa.

Em se tratando das manifestações desses gestores em relação à clareza dos documentos oficiais quanto à auxiliar no atendimento aos alunos mais capazes observam-se os seguintes resultados:

Gráfico 2:- Os documentos oficiais auxiliam no atendimento aos mais capazes

\section{Os Documentos Oficiais e o Atendimento aos mais capazes.}

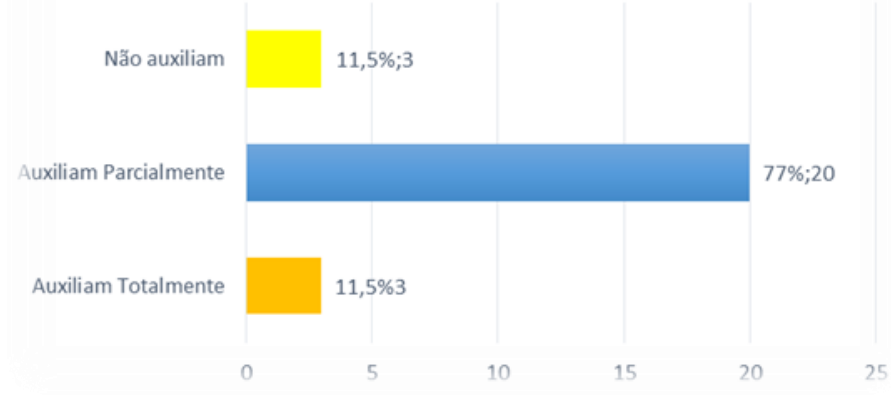

Fonte: Elaborado pelos autores. 
Quando solicitado quais eram esses documentos, as respostas surpreenderam pela impropriedade das indicações: a Constituição da República Federativa do Brasil, 1988, a LDBEN 9394/96, a Declaração de Salamanca, o Estatuto da Criança e do Adolescente, a Resolução CNE/CEB nº 02/2001, os PCNs, as publicações do MEC Saberes e Práticas da Inclusão; encontrou-se, ainda, respostas como: não há documentos que auxiliam; desconheço tal documentação no município; publicações do MEC e da $S E E / S P$ sem especificação de quais seriam.

Em relação à identificação desses estudantes as manifestações dos gestores mostram que: $65 \%$ indicam que auxiliam parcialmente; $23 \%$ não auxiliam na identificação (há um crescimento no percentual relacionado aos que não auxiliam); $12 \%$ auxiliam totalmente.

Gráfico 3: As Orientações legais auxiliam na identificação dos estudantes mais capazes

\section{ORIENTAÇÕES LEGAIS REFERENTES À IDENTIFICAÇÃO.}

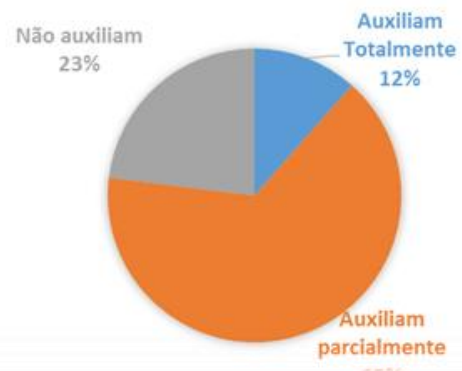

Fonte: Elaborado pelos autores.

Quando se verifica os apontamentos dos gestores em relação às orientações legais que auxiliam na identificação, aparecem os mesmos documentos legais que reconhecem a importância do atendimento, mas não tratam das formas de identificação. Apenas 5\% dos gestores indicaram as orientações e publicações do MEC, e fazem referência à aplicação de questionários; à observação realizada pelos professores das Salas de Recursos; à construção de materiais e testes específicos para avaliar o potencial dos educandos; à reclassificação por competências, utilizando os resultados de avaliações (externas e internas); à avaliação por equipe multidisciplinar.

A maioria dos gestores manifestou dificuldade de encontrar e reconhecer sinais de capacidade elevada, constatada nas manifestações: Não indicam, não ficou claro pra eu encontrar esse aluno (Gestor 10) / As orientações legais não indicam, não conheço, 
não há (Gestores 1, 2, 5, 15,19 33, 39, 40, e 41) / Acho tudo muito confuso, altas habilidades / superdotação, não consigo ver clareza para identificar os alunos que poderiam se enquadrar nesse público( Gestor 21) ${ }^{11}$.

Observa-se, na fala dos gestores acima descrita, que, mesmo com as medidas tomadas pelo MEC, por intermédio de curso de formação,

Essa situação mudou um pouco, mais em discurso que ação, com o aumento algorítmico de medidas tomadas pelo MEC, numa inundação de leis, decretos, resoluções. Nem sempre coerentes em si, e frequentemente corrigindo ou contradizendo medidas anteriores. Ao contrário do prometido apoio, a educação especial, entre nós enfrenta ataque oficial, que, além do impacto nos professores, pouco efeito faz na área, a se observar pela prática vivida nas escolas. (GUENTHER, 2013, p.21)

Nas manifestações dos gestores, encontram-se dois aspectos que colaboram com essa afirmação. O primeiro ligado à questão do mito ainda presente na área, à crença de que os mais capazes não necessitam de atenção especial, como fica claro nas falas de gestores: Não concordo que existam 'superdotados', as crianças são o que a escola e o meio possibilitam para elas (Gestor 14); Se existem superdotados, eles não precisam tanto da nossa intervenção, vão se bem dizer sozinho, terminam tudo, fazem tudo, tem boas notas. (Gestor 19). O segundo, relacionado às normativas locais evidente nas falas a seguir: Não temos, na secretaria municipal da educação leis específica para esta ação. (Gestor 12); Sei que a legislação contempla esse público, mas realmente não entendo como posso encontrar esses alunos. (Gestor 14).

Em relação aos procedimentos para identificação de crianças e jovens dotados e talentosos, 38\% dos gestores relataram que tais procedimentos não existem no município; 31\% desconhecem esses procedimentos; $4 \%$ não responderam; 4\% apontaram os testes como procedimentos; $23 \%$ indicaram: a observação do professor, o relatório pedagógico, a avaliação psicopedagógica de interesses, o encaminhamento a atendimento clínico (psicólogo), a discussão em HTPC (Hora de Trabalho Pedagógico Coletivo) e no Conselho de Classe.

$\mathrm{Na}$ categoria Intervenção Pedagógica, nota-se que apenas $8 \%$ dos gestores afirmaram que as normativas legais indicam formas de intervenção; 58\% dizem que orientam parcialmente; $15 \%$ dizem que não indicam; $19 \%$ revelam não saber.

${ }^{11}$ Santos, R.; Zaniolo, L.O. O Atendimento às crianças e jovens com Dotação e Talento: a experiência do CEDET de Assis. Santos, R. Faculdade de Ciências e Letras - UNESP - Campus Araraquara. 
Gráfico 4: As orientações legais referentes à Intervenção Educativa

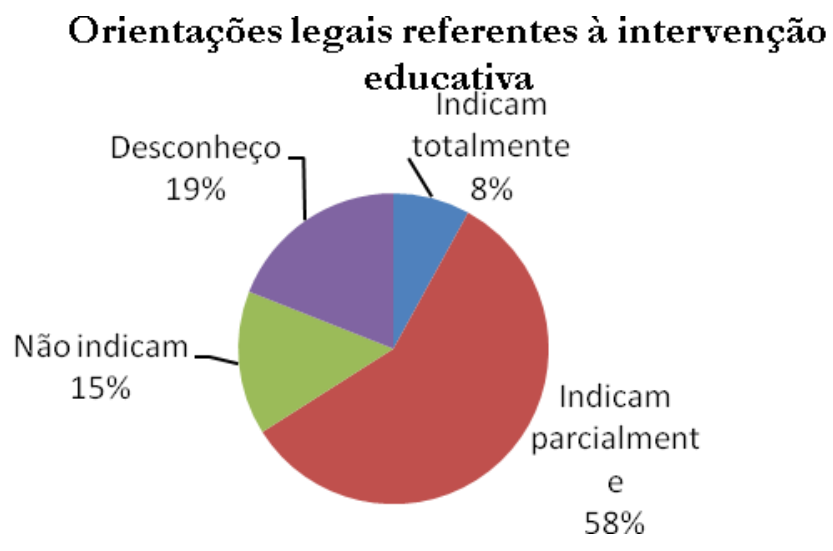

Fonte: Elaborado pelos autores.

No entanto, quando se analisa os dados de modo geral, o que se verifica é um percentual bastante alto da ausência dos sistemas de ensino no que se refere à assistência educacional aos educandos dotados e talentosos. Nas verbalizações dos gestores fica evidente a ausência de conhecimento na área, conforme manifestações a seguir:

Não há trabalho específico para esses alunos, pois nossa secretaria não tem conhecimento suficiente na área para identificá-los. (Gestor 07) As orientações legais não são muito claras, a meu ver, tenho dificuldades de compreender e identificar quem são esses alunos. Precisamos de mais estudos na área, sei de uma experiência exitosa, mas o município investiu na formação e realizou parceira com a universidade. (Gestor 08)

Os professores conseguem identificar alguns alunos com determinados talentos, e o que lemos nas orientações legais parecem fora da nossa realidade, não tem a ver com o nosso contexto, assim eles não recebem atendimento. (Gestor 26)

Pode-se inferir que as orientações e respaldos legais continuam na ideologia e, para mudar esse cenário, é preciso conhecimento científico consistente e comprovado.

A propósito desses apontamentos, Guenther (2006) afirma que, para se construir um programa que leve cada criança a desenvolver seus talentos de forma a elaborar um plano ligado às situações da vida real, acontecendo na sua comunidade, na sua escola, com seus pares, é preciso:

Em primeiro lugar estudar seriamente o assunto. Há um vasto corpo de conhecimento na área, a maior parte traduzida ou baseada em experiências de outros países, mas para alicerçar um plano de ação temos que começar com um estudo sério e amplo da própria situação local: quem são as crianças sinalizando capacidade elevada, como são as escolas em que elas estudam qual o perfil local, os anseios, estilo de 
vida, interesses, vocação e recursos materiais e humanos da comunidade onde vivem. (GUENTHER, 2006, p.32)

Ao mesmo tempo, não se pode desconsiderar que os órgãos oficiais têm demonstrado preocupação com a educação para o desenvolvimento de capacidade e talentos. No entanto, os estudantes mais capazes continuam invisíveis, não se reconhecem os domínios de capacidade, não se distinguem os sinais de dotação e talento.

Nesse sentido, continua sendo um desafio, pois a dificuldade de encontrá-los é evidenciada no grupo de gestores que responderam a questão que solicitava o número de estudantes identificados no município. Os dados revelam que apenas $4 \%$ dos gestores sinalizaram ter de um a vinte alunos com capacidade acima da média; $42 \%$ gestores responderam não existir essa demanda no município e 54\% não responderam. Esses dados estão expressos no gráfico a seguir.

Gráfico 5 - Estudantes identificados com Alta Capacidade

Número de crianças e jovens identificados.

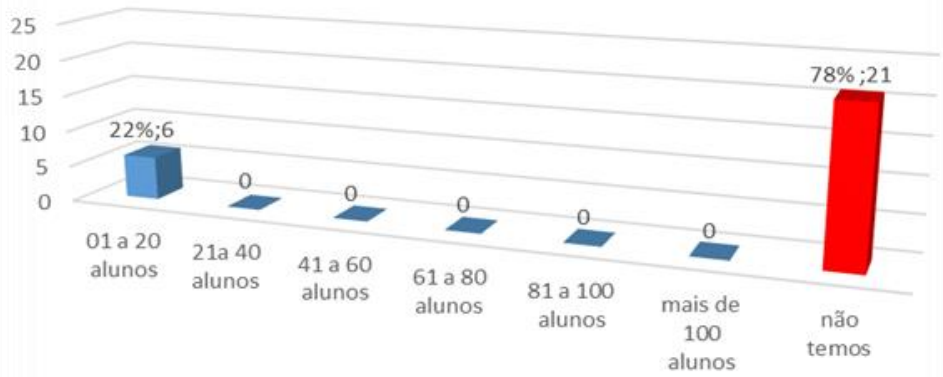

Fonte: Elaborado pelos autores.

Pode-se aliar a essa constatação os indicadores oficiais (Censo Escolar, INEP) referentes ao número de estudantes identificados e recebendo intervenção educativa específica, o qual não atinge a $1 \%$ do número de estudantes identificados; pela Lei da probabilidade, (3 a 5\% da população), o Brasil deveria ter cerca de 2,5 milhão de estudantes matriculados em nossas escolas. 
O gráfico a seguir apresenta o número de estudantes com capacidade elevada apresentado nos Censos Escolares de 2000 a 2015:

Figura 1:Número de Matriculas Estudantes com Alta Capacidade Brasil

\section{Estudantes com Alta Capacidade no Brasil}

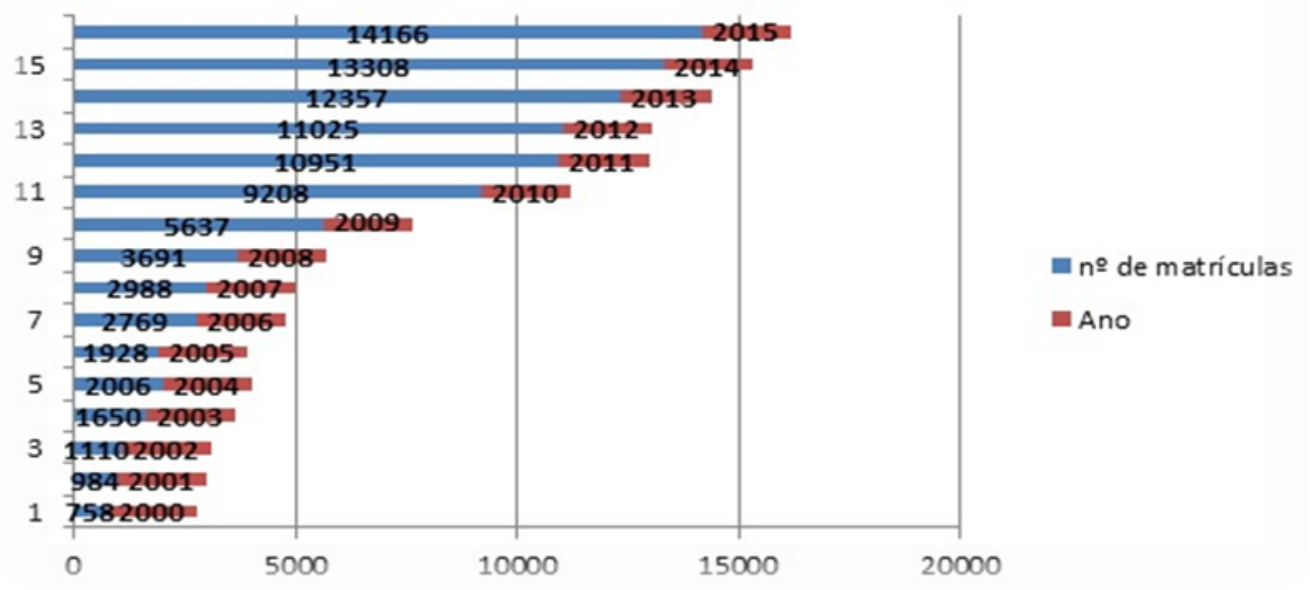

Fonte: Inep

Guenther (2013, p.23), examinando a situação no Brasil, sugere que, nos últimos anos, perdeu-se muito a atitude científica, inclusive por não abrir espaço para a avaliação e a integração do conhecimento já conquistado na área. O que se destaca é a atitude ideológica respaldada em regulamentos, legislações e orientações veiculadas por determinação oficial.

Aumentou numericamente o corpo de pesquisa no tema, mormente por teses e dissertações acadêmicas, mas não se construiu muita ciência, porque $90 \%$ das pesquisas focam leis, regulamentos e políticas, e parte dos $10 \%$ recolhe opinião sobre um ou outro tema, tomando a resposta da maioria como conhecimento estabelecido; preocupa-me o fato de que o autor mais citado em nossas bibliografia e publicações científicas é BRASIL, MEC. um autor de quem não se conhece autoridade científica, e obviamente não tem universalidade na ciência. (GUENTHER, 2013, p.23)

Portanto, pode-se inferir que, pelos textos legais, diretrizes, regulamentos, pareceres, e outros, a área não pode progredir muito. Tomando-se essa base como referencial para a análise crítica, a fim de cotejar situação oficialmente apregoada, com a situação real, buscando romper com a visão ingênua, acrítica, legalista, reprodutora e ideológica, que permeia a educação de crianças e jovens mais capazes, provavelmente não se construirá conhecimento científico de validade para a área: quem são e como se apresentam esse alunos, e que caminhos levam ao desenvolvimento de seu potencial.. 
Afonso (2014) faz uma análise das políticas públicas de educação em torno da reflexão do papel da gestão escolar no processo de efetivação dessas políticas e aponta que o reconhecimento do conhecimento tácito como fonte de expertise é uma das perspectivas que valoriza a participação de outros atores na tomada de decisão política. Dumas e Anderson (2014) assinalam a importância de não se deixar prevalecer às decisões baseadas em ideologias. Pontuam que as bases para a construção das agendas políticas não deveriam se pautar por políticas de grupos de interesses, episódios, senso comum, motivos ideológicos, e outras razões que, tipicamente, têm pouco a ver com as evidências da pesquisa ou com os modelos de tomada de decisão racional. Essa é a mesma posição adotada pelos autores do presente artigo.

No Brasil, a maioria dos programas existentes volta-se às orientações legais que aconselham programas de enriquecimento, os quais não apresentam indicadores consistentes em seus processos de identificação e de intervenção educativa, a julgar pelo irrisório percentual de estudantes apontados pelos órgãos oficiais.

Contudo, existe "luz no final do túnel" o Censo - 2015, realizado pelo INEP Instituto Nacional de Estudos e Pesquisas Educacionais Anísio Teixeira, aponta 14.166 estudantes identificados. O CEDET - Centro para Desenvolver Potencial e Talento, apenas com os dados do CEDET de Lavras - MG, que, em 2015, atendeu 553 estudantes, o que corresponde a 3,9\% dos 14.166 identificados no país, embora a população local represente somente $0,05 \%$ da população brasileira. Assim pode-se sugerir, que, no Brasil, somente o CEDET atende ao percentual estabelecido pela OMS em relação à identificação e ao oferecimento de espaços para o desenvolvimento das potencialidades desses estudantes.

Guenther (2013, p.20), na conferência de abertura do IX Encontro Internacional do CEDET/ASPAT destaca que as bases do CEDET sempre estiveram apoiadas no conhecimento científico, por ele autocorretivo, diferente da ideologia que não comporta espaços para autocorreção. A verdade no conhecimento científico não depende de ideologia, entretanto, medidas políticas dependem de quem está no poder, além disso, "conhecimento científico tem coerência interna e corresponde a uma realidade externa. Se não entendemos essa coerência, isso reflete nossa ignorância, mas não uma falha da ciência”. (GUENTHER, 2013, p.22).

\section{Considerações finais}


Como mencionado, mesmo com os respaldos legais, ainda existe dificuldade por parte dos Sistemas de Ensino para identificar e atender às crianças e aos jovens com altas capacidades; a mesma dificuldade está em compreender os termos das leis que regem as políticas para o atendimento a esses alunos, embora algumas leis tenham sido revogadas ou substituídas, essas alterações não tem se consubstanciado em avanços na área. Assim parece apropriado tomar os textos legais para aferir a situação oficialmente apregoada em termos do que seria ideal, com a situação real, buscando romper com a visão ingênua, acrítica, legalista, reprodutora e ideológica que permeia a educação desses estudantes.

Valendo-se da crítica às orientações legais que não reconhecem que os Centros para Desenvolvimento do Potencial e Talento - CEDETs atendem a legislação no que se refere à identificação e a intervenção educativa específica, como uma medida promissora, pode-se inferir que o problema, talvez esteja em definir orientações alicerçadas em apenas uma corrente teórica e avaliar os resultados dessas indicações.

Enfim, acredita-se que a eficácia de qualquer medida educativa dependa da intensidade da diferenciação, da clareza dos construtos e dos processos de identificação e intervenção. De fato há intenção de ampliar os direitos sociais e humanos, mediante a sistematização de normativas legais, porém, elas por si só não asseguram a implantação de ações necessárias e a efetivação desse direito, ou seja, a oportunidade para desenvolver o potencial superior desses escolares.

\section{Referências}

AFONSO, N. Política de Governação e Liderança das Escolas. In. Coordenação, Supervisão e Liderança. Escolas, Projetos e Aprendizagens. Org. Machado, J. e Alves, J.M. Coleção e-book. Universidade Católica Editora - Porto, 2014.

ANTIPOFF, H. Educação do Bem-Dotado, Coletâneas das obras escritas por Helena Antipoff, Vo. V, CDPHA, Belo Horizonte, MG, 1992.

BARDIN, L. Análise de conteúdo/ Laurence Bardin; tradução Luís Antero Rego, augusto Pinheiro. São Paulo: Edições 70. 2008.

CORAZZA, S.M. Diferença pura de um pós-currículo. In. LOPES, A.C.;MACEDO, E. Currículo: debates contemporâneos. São Paulo. Cortez, p.103-114 (série cultura, memória e currículo, v.2), 2005. 
DELOU, C. M. C. Educação do aluno com altas habilidades/superdotação: legislação e políticas educacionais para a inclusão. In. S. Fleith (Org.), A Construção de Práticas Educacionais para Alunos com Altas Habilidades /Superdotação: Orientação a professores, vol. 02 (pp.25-40). Brasília: Ministério da Educação. Secretaria de Educação Especial, 2007 b.

DUMAS, M. J., \& ANDERSON, G. Qualitative research as policy knowledge: Framing policy problems and transforming education from the ground up. Education Policy Analysis Archives, 22(11), 1-24, 2014.

FLEITH, D. S. Colóquio. In Revista da Educação Especial/ Secretaria de Educação Especial. V.4, n.1. Janeiro/junho, 2008.

GUENTHER, Z. C., \& FREEMAN, J. Educando os mais capazes: Ideias e ações comprovadas. São Paulo: EPU, 2000.

GUENTHER, Z. C. Capacidade e talento: um programa para a escola. São Paulo: E.P.U. 2006

GUENTHER, Z. C. Caminhos para desenvolver potencial e talento. Lavras: Ed. UFLA, 2011.

GUENTHER, Z. C., \& RONDINI, C. A. Capacidade, Dotação, Talento, Habilidades - Uma sondagem da conceituação pelo ideário dos educadores. Educação em Revista (UFMG. Impresso), 28, (01), 237-266, 2012.

GUENTHER, Z. C. O CEDET - 20 anos de vida e experiência educativa. Livro de Registro IX Encontro Internacional de Educadores do CEDET/ASPAT, Lavras, MG, p.20 -27 2013.

GUENTHER, Z. C (2011) Altasabilidades- barra- superdotação... Isso é a sério?... IV CBEE - Congresso Brasileiro de Educação Especial - CBEE: São Carlos, Associação Brasileira de Pesquisadores em Educação Especial - ABPEE; Programa de Pósgraduação em Educação Especial - PPGEEs/UFSCar - São Carlos: Santa Terezinha, 2014.

GUENTHER, Z. C. Identificação de Alunos Dotados e Talentosos: Metodologia do CEDET versão 2012. CEDET - ASPAT, Lavras, MG. 2013.

SANTOS, R; RONDINI, C.A. Educação para Dotados e Talentosos: O Projeto CEDET Assis/SP. Disponível em: http://www.assis.unesp.br/\#!/departamentos/psicologia--experimental-e-do-trabalho/damargem-ao-rio/

SANTOS, R.; ZANIOLO, L. O. O Atendimento às crianças e jovens com Dotação e Talento: a experiência do CEDET de Assis. Faculdade de Ciências e Letras - UNESP - Campus Araraquara. 2014.

SANTOS, R. LAHAM, S.A.D E SANTOS, D.N. Pedagogia UNESP/UNIVESP Educação Inclusiva e Especial: $O$ "Olhar" dos alunos. In Anais do II Congresso 
Nacional de Formação de Professores e XII Congresso Estadual Paulista sobre Formação de Educadores - Por uma revolução no campo da formação de professores. Águas de Lindóia-SP, 2014

SAVIANI, D. Escola e democracia. São Paulo: Cortez, 1987.

\section{LEGISLAÇÃO CONSULTADA}

BRASIL. Lei $\mathrm{n}^{\mathrm{o}}$ 4014/61, de 20 de dezembro de 1961. Diretrizes e Bases para a Educação Nacional. Disponível em: http://wwwp.fc.unesp.br/ lizanata/LDB\%20402461.pdf

BRASIL. Lei n5692/71, de 11 de agosto de 1971. Diretrizes e bases para a educação nacional. Diário Oficial da República Federativa do Brasil, Brasília, 12 ago. 1971. Disponível em: http://www.planalto.gov.br/CCIVIL_03/leis/L5692.htm

BRASIL. Constituição $\quad$ Federal, $1988 . \quad$ Disponível em: http://www.planalto.gov.br/ccivil_03/Constituicao/Constituicao.htm

BRASIL. Lei n9394, de 20 de dezembro de 1996. Diretrizes e bases para a educação nacional. Diário Oficial da República Federativa do Brasil, Brasília, 23 dez.1996. Disponível em: http://www.planalto.gov.br/CCIVIL_03/leis/L9394.htm

BRASIL. CNE/CEB. Resolução no 2/2001, de 11 de setembro de 2001. Institui Diretrizes Nacionais para a Educação Especial na Educação Básica. Brasília, Conselho Nacional de Educação, 2001.

BRASIL. Ministério da Educação. Secretaria de Educação Especial. Diretrizes Nacionais para educação especial na educação básica. MEC; SEESP, 2001. Disponível em: http://portal.mec.gov.br/seesp/arquivos/pdf/diretrizes.pdf

BRASIL. Ministério da Educação. Política Nacional da Educação Especial na perspectiva da Educação Inclusiva. Brasília: MEC/SECADI, 2008. Disponível em: http://portal.mec.gov.br/index.php?option=com_docman\&view=download\&alias=1669 0 -politica-nacional-de-educacao-especial-na-perspectiva-da-educacao-inclusiva05122014\&Itemid=30192

BRASIL. Ministério da Educação. Decreto no 7611, de 17 de novembro de 2011. Disponível em: http://www.planalto.gov.br/ccivil_03/_ato20112014/2011/decreto/d7611.htm

BRASIL. Ministério da Educação. Instituto Nacional de Estudos e Pesquisas Educacionais Anísio Teixeira. Número de matrículas educação especial, por nível de ensino e tipo de necessidade especial, Brasília. Disponível em: http://download.inep.gov.br/educacao_basica/censo_escolar/resumos_tecnicos/resumo_t ecnico_censo_educacao_basica 
BRASIL. Ministério da Educação. Lei no 12.796, de 04 de abril de 2013. Brasília: MEC, 2013. Disponível em: http://www.planalto.gov.br/ccivil_03/_ato20112014/2013/lei/l12796.htm

BRASIL. Ministério da Educação. LEI No 13.234, DE 29 DE DEZEMBRO DE 2015. Brasília: MEC, 2015. Disponível em: http://www.planalto.gov.br/ccivil_03/_Ato20152018/2015/Lei/L13234.htm

\section{Como referenciar este artigo}

SANTOS, Rosimeire dos.; GUENTHER, Zenita Cunha.; ZANIOLO, Leandro Osni. EFEITOS DA LEGISLAÇÃO PARA A EDUCAÇÃO DE DOTADOS E TALENTOSOS: o que dizem os gestores escolares. Revista on line de Política e Gestão Educacional, Araraquara/SP, v.20, n.03 , p. 643-667, 2016. Disponível em: <http://dx.doi.org/10.22633/rpge.v20.n3.9768>. ISSN: 1519-9029.

Submetido em: junho/2016

Aprovado em: agosto/2016 